Multifunctional poly(alkyl methacrylate) films for dental care

This article has been downloaded from IOPscience. Please scroll down to see the full text article.

2011 Biomed. Mater. 6015003

(http://iopscience.iop.org/1748-605X/6/1/015003)

View the table of contents for this issue, or go to the journal homepage for more

Download details:

IP Address: 148.197.220.45

The article was downloaded on 06/01/2011 at 09:25

Please note that terms and conditions apply. 


\title{
Multifunctional poly(alkyl methacrylate) films for dental care
}

\author{
Birthe V Nielsen ${ }^{1,2}$, Thomas G Nevell ${ }^{1}$, Eugen Barbu ${ }^{1}$, James R Smith ${ }^{1}$, \\ Gareth D Rees $^{3}$ and John Tsibouklis ${ }^{1,4}$ \\ ${ }^{1}$ School of Pharmacy and Biomedical Sciences, University of Portsmouth, Portsmouth, Hampshire, \\ PO1 2DT, UK \\ ${ }^{2}$ School of Science, University of Greenwich, Chatham Maritime, Kent, ME1 4TB, UK \\ ${ }^{3}$ GlaxoSmithKline R\&D, St George's Avenue, Weybridge, Surrey, KT13 0DE, UK
}

Received 5 October 2010

Accepted for publication 1 December 2010

Published 5 January 2011

Online at stacks.iop.org/BMM/6/015003

\begin{abstract}
Towards the evaluation of non-permanent dental coatings for their capacity to impart dental-care benefits, thin films of a homologous series of comb-like poly(alkyl methacrylate)s (ethyl to octadecyl) have been deposited, from aqueous latex formulations, onto dentally relevant substrates. AFM studies have shown that the thickness $(40-300 \mathrm{~nm})$ and surface roughness $(8-12 \mathrm{~nm})$ of coherent polymer films are influenced by the degree of polymerization and by the length of the pendant chain. Of the polymers under consideration, poly(butyl methacrylate) formed a close-packed film that conferred to dental substrates a high degree of inhibition to acid-mediated erosion (about 27\%), as evaluated by released-phosphate determinations. The potential utility of the coatings to act as anti-sensitivity barriers has been evaluated by determining the hydraulic conductance of coated bovine-dentine substrates; single treatments of dentine discs with poly(butyl methacrylate) or with poly(ethyl methacrylate) effected mean respective reductions in fluid flow of about $23 \%$ with respect to water-treated controls; repeated applications of the poly(butyl methacrylate) latex led to mean reductions in fluid flow of about $80 \%$. Chromometric measurements have shown that pellicle-coated hydroxyapatite discs treated with poly(butyl methacrylate), poly(hexyl methacrylate) or poly(lauryl methacrylate) exhibit significant resistance to staining by food chromogens.
\end{abstract}

(Some figures in this article are in colour only in the electronic version)

\section{Introduction}

Dental caries, dentine hypersensitivity and dental erosion are preventable conditions that are often attributable to dietary lifestyle [1, 2]. The search for improved anti-sensitivity actives and for innovations in prophylaxis is driven by the therapeutic needs of the estimated $8-30 \%$ of the adult population affected by sensitive teeth [3, 4]. One approach involves the use of hydrophobic polymer-based materials as occlusive thin films for the prophylaxis of dental erosion and dentine hypersensitivity [5]. The rationale is based on the effective delivery of the polymer to the oral cavity to form a continuous thin film on dental hard tissue surfaces, and on the film's physicochemical properties delivering the required

4 Author to whom any correspondence should be addressed. benefits. The primary function of the film is to inhibit the erosive demineralization of enamel and dentine by acting as a barrier to the diffusion both of acid species from the oral cavity to mineral surfaces and of dissolved mineral ions in the reverse direction. For this, the film must be sufficiently robust for its protective effect not to be lost under the normal conditions that operate in situ.

A typical dietary intake results in frequent and often considerable changes in $\mathrm{pH}$ and temperature during the course of a day, and the shear forces associated with speech and mastication are significant. The polymeric film may also provide relief from dentine hypersensitivity, depending on its capacity to occlude previously patent dentinal tubules, such that the transmission of external stimuli to the mechanoreceptors located at the odontoblast/pulp interface is prevented. Other relevant considerations include the 
Table 1. Poly(alkyl methacrylate)s (PAMA, $\left[\mathrm{CH}_{2} \cdot \mathrm{C}\left(\mathrm{CH}_{3}\right)\left(\mathrm{CO}_{2} \mathrm{R}\right)\right]_{x}$ ): average relative molar mass, $M$; surface energy, $\gamma$ (from liquid drop contact angle measurements on films deposited on glass plates); glass transition temperature, $T_{g}$ (from differential scanning calorimetry); and range and mean of polymer latex particle sizes, $\mathbf{d}(n=6)$.

\begin{tabular}{llllllll}
\hline$R$ & Acronym & $M\left(10^{5}\right)$ & $x_{\text {average }}\left(10^{3}\right)$ & $\gamma\left(\mathrm{mJ} \mathrm{m}^{-2}\right)$ & $T_{g}\left({ }^{\circ} \mathrm{C}\right)$ & Range of $d(\mathrm{~nm})$ & Mean $d( \pm \mathrm{SD})(\mathrm{nm})$ \\
\hline Ethyl & PEMA & 5.2 & 4.5 & 33.6 & 65 & $96-219$ & $197(8)$ \\
Butyl & PBMA & 3.4 & 2.6 & 28.8 & 20 & $30-95$ & $74(12)$ \\
Hexyl & PHxMA & 4.0 & 2.4 & 23.1 & -5 & $92-96$ & $94(3)$ \\
Lauryl (dodecyl) & PLMA & 5.8 & 2.3 & 19.1 & -70 & $53-96$ & $91(7)$ \\
Hexadecyl & PHMA & 2.0 & 0.65 & - & 15 & $88-95$ & $91(5)$ \\
Octadecyl & POMA & 1.7 & 0.42 & 17.6 & -100 & $30-95$ & $73(14)$ \\
\hline
\end{tabular}

toxicological profile of the polymer, its preferred dosage form and its frequency of application. Finally, the anticipated antierosion benefit conferred by the hydrophobic thin film should be balanced against its potential adverse effect on the uptake of fluoride by enamel and dentine. The anti-erosion efficacy of fluoride has been demonstrated in vitro and in situ and its anti-caries activity is considered responsible for the major improvements in dental health that have been observed over the past 30-40 years [6-8].

In addition to their potential utility as inhibitors of dental erosion and of dentine hypersensitivity, polymeric film coatings may offer dental-care benefits relating to tooth staining, microbial binding and biofilm formation or detachment. In the latter regard, polymeric materials that can be deposited as low-surface-energy films are of particular interest $[5,9,10]$. The low-surface-energy approach to antifouling is underpinned by the DLVO theory [11, 12]. In physiological environments the ultra-low-surface-energy coatings should minimize the van der Waals interactions between the surface and prospective bacterial colonizers (predominantly negatively charged), such that the net forces of the interaction become repulsive over relatively large distances [13]. The hypothesis has been tested by measuring the surface free energy, and the resistance to microbial adhesion under the relevant physiological conditions, of a wide range of synthetic polymers that have been prepared as thin films. Those structured around the poly(acrylate) or poly(methacrylate) backbone have shown particular promise [5, 14, 15], and this study extends this work by examining, in vitro, the potential dental-care benefits of aqueous latex-deposited poly(alkyl methacrylate) coatings [16] on hydroxyapatite (HA) as a nonbiological model of human enamel [17].

\section{Materials and methods}

\subsection{Polymer latex formation}

Poly(alkyl methacrylate)s $\left(\left[\mathrm{CH}_{2} \cdot \mathrm{C}\left(\mathrm{CH}_{3}\right)\left(\mathrm{CO}_{2} \mathrm{R}\right)\right]_{x}\right.$, table 1) were sourced from Sigma-Aldrich, Gillingham, UK, or from Schnelldorf, Germany. The samples of poly(butyl methacrylate), PBMA, and of poly(ethyl methacrylate), PEMA, were used as received. Poly(hexyl methacrylate), PHxMA, poly(lauryl methacrylate), PLMA, poly(hexadecyl methacrylate), PHMA, and poly(octadecyl methacrylate), POMA, which were received as solutions in toluene, were precipitated $(\times 2)$ by cold methanol (liquid nitrogen). Polymers were dissolved in deuterated chloroform and were characterized using nuclear magnetic resonance (NMR) spectroscopy (Jeol GSX, 400 and $100 \mathrm{MHz}$ respectively for ${ }^{1} \mathrm{H}$ and ${ }^{13} \mathrm{C}$ NMR). The complete removal of toluene was established from the spectra: ${ }^{1} \mathrm{H}$ at $6.5-8.5 \mathrm{ppm}$ and ${ }^{13} \mathrm{C}$ NMR at $159 \mathrm{ppm}$. All polymers were of sufficiently high average molecular weight to exhibit consistent properties $(>17000$; table 1).

Dispersions $(2.8 \% \mathrm{w} / \mathrm{w})$ were prepared by dissolving each polymer $(450 \mathrm{mg}$ ) into, as appropriate, dichloromethane (PEMA), diethyl ether (PBMA) or petroleum ether (3.0 g) and then adding this solution (drop-wise, $2 \mathrm{~min}$ ) into an aqueous solution of sodium dodecyl sulfate (SDS, Acros Organics, $15 \mathrm{~g}, 0.50 \% \mathrm{w} / \mathrm{w}$ ) under sonication (Ultrasonic Processor, amplitude $37 \%, 7 \mathrm{~min}$ ). To remove the organic solvent, the latex was stirred at $5 \mathrm{~K}$ above the solvent boiling point (4-6 h, small amounts of DIW added periodically to maintain volume). After cooling to ambient temperature, DIW was added to give a final batch mass of $15.45 \mathrm{~g}$. To facilitate the determinations of dry mass and particle size distribution, the aqueous phase was removed following separation by centrifugation $(4000 \mathrm{rpm}$, 5 min). Particle size profiles were obtained using a COULTER ${ }^{\circledR}$ N4MD Sub-Micron Particle Analyser, equipped with multiple scattering angle detection and with Size Distribution Processor Analysis software. Each latex was diluted with water $(1: 50,1: 25,1: 10)$ in a quartz cuvette to obtain sample intensity readings at a detection angle of $90^{\circ}$ of between $5 \times 10^{4}$ and $1 \times 10^{6}\left(20^{\circ} \mathrm{C} ; 120 \mathrm{~s}\right)$. Mean particle sizes and size distributions were similar for all poly(alkyl methacrylate)s latexes investigated (table 1).

\subsection{Samples of dental materials}

HA discs (diameter $=12.5 \mathrm{~mm}$, thickness range $=1.0$ $1.3 \mathrm{~mm}$, about $0.46 \mathrm{~g}$; Himed USA, Old Bethpage, New York) were pre-etched in an aqueous citric acid solution $(1.0 \% \mathrm{w} / \mathrm{v}$ adjusted to pH 3.5 with $\mathrm{NaOH}$; six discs per $500 \mathrm{~mL}, 30 \mathrm{~min}$, repeated twice). Excess acid was removed by rinsing (DIW) and the discs were stored under DIW.

To deposit a salivary pellicle, whole stimulated human saliva (produced by chewing Parafilm ${ }^{\circledR}$ ) was collected in sterile tubes $\left(0{ }^{\circ} \mathrm{C}\right)$ and centrifuged $(8000 \mathrm{rpm}, 10 \mathrm{~min}$, $4{ }^{\circ} \mathrm{C}$ ) to remove particulate material and cell debris. The mucin-containing supernatant $(20 \mathrm{~mL}$, with sodium azide, $8 \mathrm{mg}$, to prevent bacterial growth) was poured to cover the prepared HA discs $(\times 12)$. The containing vessel was held at $37{ }^{\circ} \mathrm{C}$ for $2 \mathrm{~h}$. The pellicle-coated HA discs were rinsed (DIW), dried $\left(37^{\circ} \mathrm{C}, 24 \mathrm{~h}\right)$ and stored in a desiccator. 

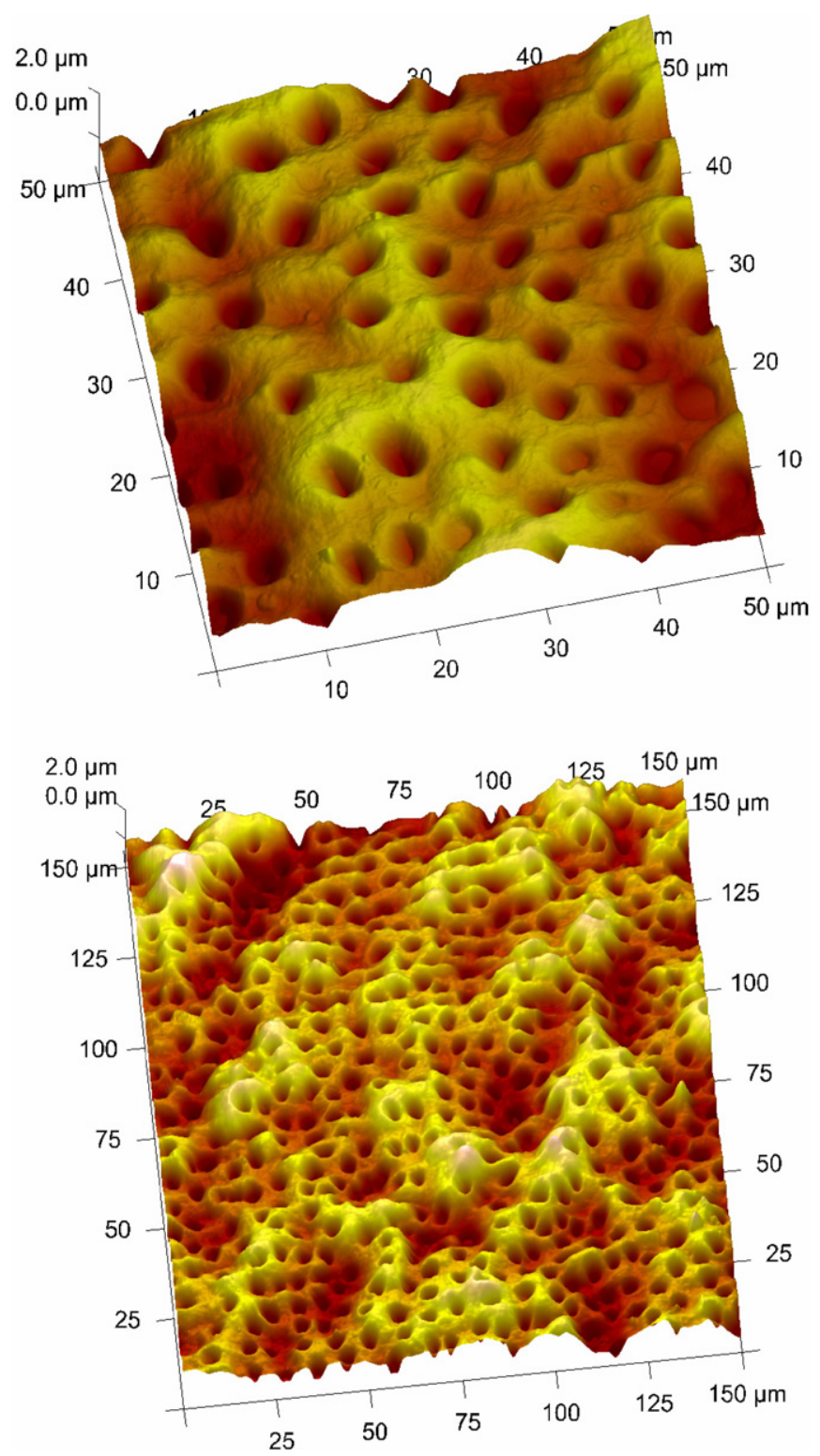

Figure 1. AFM images $(50 \mu \mathrm{m} \times 50 \mu \mathrm{m}$ and $150 \mu \mathrm{m} \times 150 \mu \mathrm{m})$ of sections of bovine teeth following etching with an aqueous citric acid solution ( $10 \% \mathrm{w} / \mathrm{v}, 2 \mathrm{~min})$. Surface undulations are attributed to sample processing; openings of tubules normal to the cut surface are shown.

Bovine teeth, sterilized by immersion in (1) aqueous $\mathrm{NaOCl}, 5.0 \% \mathrm{v} / \mathrm{v}, 2$ min, and (2) aqueous $\mathrm{H}_{2} \mathrm{O}_{2}, 30 \%, 2$ min, were checked for decay (by probing any fissures) and stored in aqueous saline $(0.9 \% \mathrm{w} / \mathrm{v} \mathrm{NaCl})$. Dentine discs $(0.8 \mathrm{~mm}$ thickness) were prepared by sectioning the tooth (Isomet 1000 precision saw: weight shaft loading $175 \mathrm{~g}$, saw speed 200$250 \mathrm{rpm}$; the blade was immersed $\left(\frac{1}{4}\right.$ inch) into the lubriant solution $\left(0.3 \% \mathrm{w} / \mathrm{v}\right.$ Tween $20,0.06 \% \mathrm{w} / \mathrm{v} \mathrm{H}_{2} \mathrm{O}_{2}, 0.005 \%$ $\mathrm{NaHCO}_{3}$ ) and was aligned parallel to the occlusal surface, below the crown but above the root canal). To remove the smear layer formed during cutting and to expose the dentinal tubules (figure 1), each disc was etched (aqueous citric acid $10 \% \mathrm{w} / \mathrm{v}, 2 \mathrm{~min})$ and rinsed $(\mathrm{DIW} \times 5)$. The dentine discs were stored under aqueous saline $(0.90 \% \mathrm{w} / \mathrm{v})$.

\subsection{Polymer-film formation and AFM imaging}

Polymer latexes $(2.8 \% \mathrm{w} / \mathrm{w})$ were filtered $(0.2 \mu \mathrm{m}$ PTFE$)$. Using a constant speed motor: (dipping speed $=10 \mathrm{~mm} \mathrm{~s}^{-1}$; raising speed $=1 \mathrm{~mm} \mathrm{~s}^{-1}$ ) films were deposited onto substrates (pellicle-coated HA discs, chromic acid-washed glass), which were then allowed to dry $\left(37^{\circ} \mathrm{C}, 24 \mathrm{~h}\right)$.

For AFM, polymer-coated plane glass samples $(10 \times$ $10 \mathrm{~mm}^{2}$, extra white glass; Menzel-Gläser, ThermoScientific, Loughborough, UK) were secured on nickel sample holders. Images were obtained in contact mode using a MultiMode/NanoScope IV Scanning Probe Microscope (Digital Instruments, Santa Barbara, CA, USA) equipped with a J-scanner capable of a maximum $x, y, z$-translation of $200 \times 200 \times 16 \mu \mathrm{m}^{3}$. A 'D' V-shaped cantilever ('NP'; nominal length $\left(l_{\text {nom }}\right)=196 \mu \mathrm{m}$, width $\left(w_{\text {nom }}\right)=23 \mu \mathrm{m}$, resonant frequency $\left(v_{\text {nom }}\right)=18 \mathrm{kHz}$, spring constant $\left(k_{\text {nom }}\right)=$ $0.06 \mathrm{~N} \mathrm{~m}^{-1}$; Veeco Instruments SAS) was used.

\subsection{Acid demineralization}

The progressive demineralization by aqueous citric acid of pre-etched HA discs was monitored by ICP-MS analysis of ${ }^{31} \mathrm{P}$ in liquid samples $(100 \mu \mathrm{L})$.

The Agilent ICP-MS 7500 was operated in standard mode with argon as carrier gas, necessitating the elimination of $\left[{ }^{14} \mathrm{~N}^{16} \mathrm{O}^{1} \mathrm{H}\right]^{+}$and/or $\left[{ }^{15} \mathrm{~N}^{16} \mathrm{O}\right]{ }^{+}$from the experimental protocol [18]. Each sample was digested in aqueous $\mathrm{HCl}$ (analytical grade $14 \mathrm{~g}, 0.6 \% \mathrm{w} / \mathrm{w}$ in HPLC-grade water) and all glassware and equipment were washed $(\mathrm{HCl}, 3.0 \% \mathrm{w} / \mathrm{w})$ and rinsed (HPLC-grade water, $\times 3$ ). The calibration curve for ${ }^{31} \mathrm{P}$ was constructed using acidified (aqueous $\mathrm{HCl}, 0.6 \% \mathrm{w} / \mathrm{w}$ ) phosphate solutions $\left(1-110 \mu \mathrm{g} \mathrm{L}^{-1}\right.$ as $\left(\mathrm{NH}_{4}\right)_{2} \mathrm{HPO}_{4} ; R^{2}=$ 1.000). Allowing for the background response, a detection limit of about $5 \mu \mathrm{g} \mathrm{L}^{-1}$ was determined for ${ }^{31} \mathrm{P}$ in the diluted sample, equivalent to a phosphate concentration of about $15 \mu \mathrm{g} \mathrm{L}^{-1}$.

Experiments were performed using a 12-station synthesis carousel (Radleys Discovery Technologies) in which untreated HA discs (pre-etched, pre-weighed, about $0.46 \mathrm{~g}$ ), held by stainless steel wire mesh supports in individual tubes with magnetic stirrers (maximum rate, about $1000 \mathrm{rpm}$ ), were immersed (with intermediate washings in DIW) in a series of media $\left(15 \mathrm{~mL}, 37^{\circ} \mathrm{C}\right)$. Firstly an erosion medium of aqueous citric acid (1.0\% w/w, pH 3.75) was used to establish baseline dissolution rates, by analysing samples taken at specified elapsed times. The discs were then treated (120 s) with polymer latex or control media (negative, DIW; positive, $300 \mathrm{mg} \mathrm{kg}^{-1}$ fluoride as the sodium salt). Dissolution rates were subsequently determined once again using fresh citric acid. With each disc/specimen being used as its own control, the efficacy of each treatment was expressed as the mean reduction $(n=4-6)$ in the amount of released phosphate as a proportion of that released from the untreated disc. Statistical analysis of the results was performed using a one-way ANOVA with a post hoc Fisher test. 


\subsection{Hydraulic conductance measurements}

Hydraulic conductance $\left(H_{c}\right)$ measurements were performed on dentine discs using a Pashley Flow apparatus $[19,20]$ prerinsed, and with the sample chamber (upward flow) then filled, with Earle's Balanced Salts (Sigma Aldrich). With a disc mounted in the chamber at an angle of $35^{\circ}$ from the horizontal, a hydrostatic pressure of 12 psi was applied while the disc was brushed over (artist's flat brush, $5 \mathrm{~mm}$ ) with aqueous $\mathrm{KCl}$ $(0.17 \% \mathrm{w} / \mathrm{v})$. After releasing the pressure, saliva was brushed onto the disc (1 min) and allowed to stay in contact with the disc for a further $4 \mathrm{~min}$ before the baseline flow was monitored (12 psi, 5-10 $\mathrm{min}$ ). With the pressure released, the surface was irrigated with fresh saliva, brushed with five drops of the test solution, and then rinsed (after $45 \mathrm{~s}$; aqueous $\mathrm{KCl}$ ). Saliva was applied and left undisturbed for $45 \mathrm{~s}$ before the pressure was increased and the flow rate was recorded (12 psi, 5-10 min). Measurements of the flow rate through salivatreated dentine sections were obtained both after 1 treatment with latex and following 12 successive such treatments. PA18 $(3 \% \mathrm{w} / \mathrm{v})$, Sensodyne Original (1:3 slurry in DIW) and DIW were employed respectively as positive control, benchmark control and negative control.

\subsection{Staining}

The staining solution consisted of standardized filtered tea infusion (prepared in boiling DIW; absorbance $0.50 \mathrm{~cm}^{-1}$ at $600 \mathrm{~nm}$ ). Polymer-coated, pellicilized HA discs and uncoated controls (each $\times 4$ ) were incubated individually in a staining solution $\left(100 \mathrm{~mL}, 37^{\circ} \mathrm{C}, 2 \mathrm{~h}\right)$, rinsed (DIW), dried $\left(37^{\circ} \mathrm{C}, 24 \mathrm{~h}\right)$ and stored (desiccator). The extent of staining was assessed from reflectance measurements made using a Hunter LabScan XE Spectrophotometer (Hunter Associates Laboratory, Reston, VA) equipped with a Xenon flash lamp filtered to approximately CIE D65 illumination. Four readings were taken from each HA disc, by rotating it by $90^{\circ}$ between each measurement. The chromametric reflectance measurements complied with the recommendations of the 1976 CIELAB convention of the Commission Internationale de l'Eclairage (CIE: lightness $L^{*}$ in grey scale, black $=0$ to white $=1 ; a^{*}$ and $b^{*}$ enumerate respectively the degrees of green/red and blue/yellow colours).

\section{Results and discussion}

\subsection{Poly(alkyl methacrylate) films}

Plaque formation in vivo is believed to originate from pits and grooves present on the tooth surface, with bacterial colonization favoured by surfaces with an average roughness $R_{a}>200 \mathrm{~nm}$ [21-23]. As a consequence, a desirable feature of an exogenous polymeric film formed on the surface of dental hard tissue is that it should be relatively smooth. For the films of poly(alkyl methacrylate)s formed on glass slides (figure 2) film thickness was estimated from AFM peak-to-valley topology data, it being assumed that flat $\left(R_{a}<0.1 \mathrm{~nm}\right)$ surfaces in between polymer clusters were uncoated glass [24]. Height profiles within the film-covered areas were used to calculate the values of $R_{a}$. The film thicknesses were $40-60 \mathrm{~nm}$ for PBMA, PHMA and POMA, and 60-70 nm for PHxMA and PLMA, but PEMA was exceptional with a thickness of about $300 \mathrm{~nm}$ and with relatively large areas of uncovered glass between tall deposits of polymer. Similarly, the values of $R_{a}$ were about $11 \mathrm{~nm}$ for PBMA, PLHA and PHMA but higher for PEMA and PHxMA, and lower for POMA. These characteristics appear to have been influenced by both the degree of polymerization ( $x_{\text {avereage }}$, table 1$)$ and the length of the side chain. The PBMA latex, appeared to form a more closely packed film than other poly(alkyl methacrylate)s (figure 2), which may be attributed to differences in glass transition temperature $\left(T_{g}\right)$ at the film surface and in the bulk of this material [25]. By contrast and as also found by Armstrong and Wright [26], coatings of PEMA formed partially coalesced structures with some discrete spheres (diameter about $250 \mathrm{~nm}$ ) similar in size to the average particles of the latex.

\subsection{The HA dissolution model}

The potential use of polymer films to inhibit dissolution of dental hard tissue was tested in vitro by subjecting coated HA discs, with positive and negative controls, to controlled demineralization conditions (citric acid $1.0 \% \mathrm{w} / \mathrm{v}, \mathrm{pH} 3.75$, $37{ }^{\circ} \mathrm{C}$, with stirring) using the reaction carousel. Treatment of HA with fluoride typically results in the formation of fluorhydroxyapatite (FHAP, $\mathrm{Ca}_{10}\left(\mathrm{PO}_{4}\right)_{6} \mathrm{OHF}$ ) and fluorapatite (FAP, $\left.\mathrm{Ca}_{10}(\mathrm{PO} 4)_{6} \mathrm{~F}_{2}\right)$, whose reduced solubility inhibits the lactic acid-driven demineralization of dental hard tissue and promotes re-mineralization [27-29]. In this study, aqueous fluoride (300 mg kg $\mathrm{mg}^{-1}$ as $\mathrm{NaF}$ ) was employed as a positive control treatment since preliminary experiments involving pretreatment $(120 \mathrm{~s})$ of $\mathrm{HA}$ discs with aqueous $\mathrm{NaF}$ showed inhibition $I$ of dissolution $(I=$ proportional reduction in dissolved $P$ ) increasing with both fluoride concentration and erosion exposure time $\left(250 \mathrm{mg} \mathrm{kg}^{-1}\right.$ fluoride: $I=10( \pm 3) \%$ at $5 \mathrm{~min}$ to $22( \pm 6) \%$ at $40 \mathrm{~min} ; 2000 \mathrm{mg} \mathrm{kg}^{-1}$ fluoride: $I=22$ $( \pm 12) \%$ at $5 \mathrm{~min}$ to $42( \pm 8) \%$ at $40 \mathrm{~min})$. Correspondingly, pre-treatment with DIW (negative control) gave results that were indistinguishable from those for untreated HA discs.

Dissolution rates were determined by discontinuous analysis of phosphate release, using ICP-MS. In experiments without anti-erosion pre-treatment, $<4 \%$ of the HA was dissolved and $<6 \%$ of the citric acid was consumed. The inhibition of erosion by pre-treatment with $300 \mathrm{mg} \mathrm{kg}^{-1} \mathrm{~F}^{-}$ was pronounced, highly significant $(p<0.01)$ and increased ( $I=35 \%$ to $50 \%$ ) with increasing erosion time (table 2$)$. The poly(alkyl methacrylate)s, except for PEMA which showed no inhibition, produced the values of $I$ that remained constant (within the range of data) for the duration of each experiment. The degree of inhibition conferred by polymers with longer side chains was small, and did not differ significantly from the negative control. However, PBMA and PHxMA gave consistent inhibitions of about $27 \%$ and $19 \%$ respectively and were statistically significant versus the negative control $(p<0.01)$. This may indicate a higher affinity of the shorter pendent-chain polymers for HA, due to the polar ester functionality (that is likely to bind to HA) being less shielded 


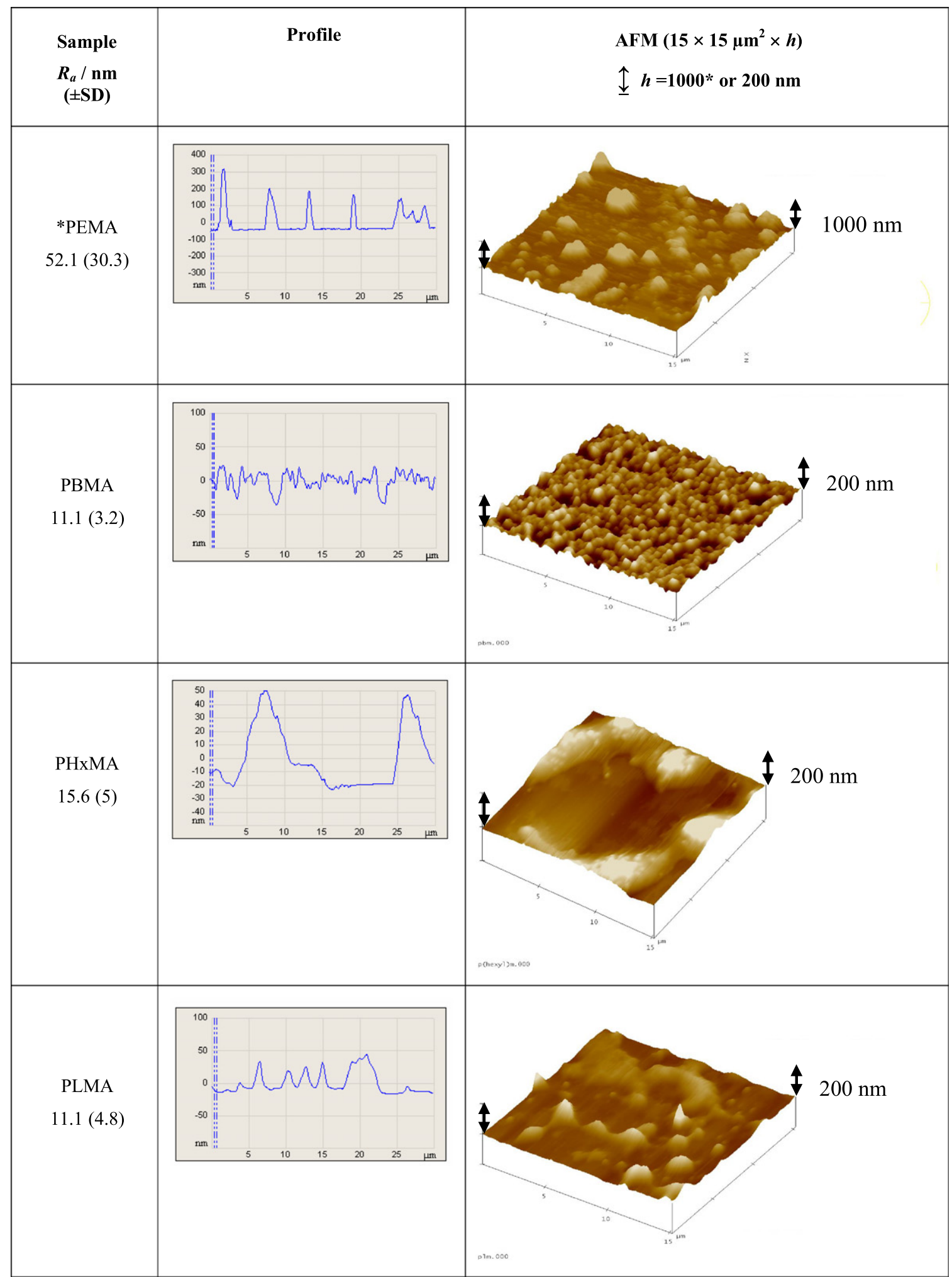

Figure 2. Typical one-line topology and AFM images (15 $\mu \mathrm{m} \times 15 \mu \mathrm{m}$; vertical scales 0-1000 nm for *PEMA, 0-200 nm for others) of latex-deposited polymer films on glass; $n=32$.

by the shorter non-polar moiety. Alternatively, the aqueous buffer may provide a suitable environment for the preferential association of the longer side-chain polymers into micellar structures. The anomalous performance of PEMA may be due to its poor film-forming behaviour at $37^{\circ} \mathrm{C}$, a consequence of its relatively high $T_{g}\left(65^{\circ} \mathrm{C}\right)$. 


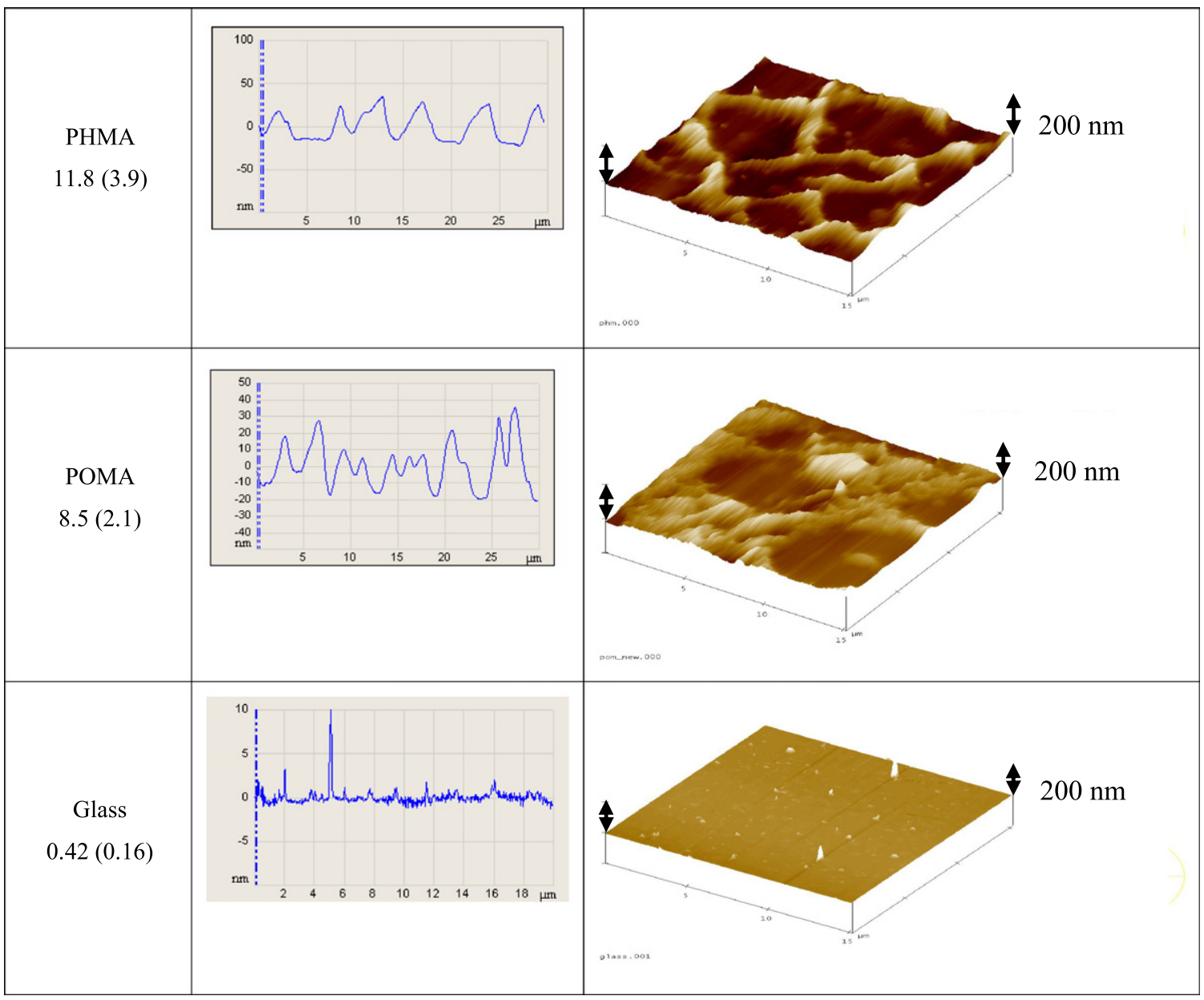

Figure 2. (Continued).

Table 2. Relative reduction, $I$, in phosphate released into citric acid $(1.0 \% \mathrm{w} / \mathrm{v}, \mathrm{pH} 3.75)$ over specified times from coated HA discs and from fluoride controls, $n 4$; superscript a denotes that the mean varies significantly from the water control (one-way ANOVA with a post hoc Fisher's test, $p<0.01$ ).

\begin{tabular}{lccccc}
\hline & \multicolumn{5}{c}{$I( \pm \mathrm{SD}) / \%$} \\
\cline { 2 - 6 } Treatment & $5 \mathrm{~min}$ & $10 \min$ & $15 \min$ & $20 \min$ & $30 \min$ \\
\hline $300 \mathrm{mg} \mathrm{kg}^{-1} \mathrm{~F}^{-}$ & $35(7)^{\mathrm{a}}$ & $41(7)^{\mathrm{a}}$ & $44(4)^{\mathrm{a}}$ & $45(7)^{\mathrm{a}}$ & $50(9)^{\mathrm{a}}$ \\
Water & $-2(7)$ & $-9(13)$ & $-8(1)$ & $-7(10)$ & $-3(6)$ \\
PEMA & $0(7)$ & $-5(5)$ & $-2(7)$ & $-3(6)$ & $0(4)$ \\
PBMA & $28(7)^{\mathrm{a}}$ & $26(5)^{\mathrm{a}}$ & $26(6)^{\mathrm{a}}$ & $26(6)^{\mathrm{a}}$ & $26(7)^{\mathrm{a}}$ \\
PHxMA & $20(8)^{\mathrm{a}}$ & $18(6)^{\mathrm{a}}$ & $18(6)^{\mathrm{a}}$ & $19(6)^{\mathrm{a}}$ & $18(5)^{\mathrm{a}}$ \\
PLMA & $3(15)$ & $-7(6)$ & $1(14)$ & $2(13)$ & $5(11)$ \\
PHMA & $9(10)$ & $8(10)$ & $8(7)$ & $11(8)$ & $9(7)$ \\
POMA & $1(8)$ & $3(9)$ & $6(8)$ & $5(7)$ & $6(4)$ \\
\hline
\end{tabular}

\subsection{Effect of polymer treatment on dentine permeability}

The efficacy of the polymer films as occlusion-effecting antisensitivity actives has been evaluated in vitro using a Pashley flow apparatus to determine the flow of simulated dentinal fluid through each dental-disc specimen under conditions of constant hydrostatic pressure. The approach has been rationalized on the basis that the extent to which treatment of the dental specimens with whole human saliva and/or putative occlusion-based actives reduces fluid flow is indicative of the extent to which the same treatment may prevent transmission of external stimuli in vivo. Owing to considerable specimen variability, measurements of hydraulic conductance were performed with each dental disc acting as its own control; fluid flow was determined following a saliva treatment (the baseline treatment) and again after treatment with each polymer or test formulation.

The mean percentage reductions in fluid flow consequent to brushing (30 s) dental discs with each of the poly(alkyl methacrylate) dispersions is summarized in table 3 . With the exception of PHxMA, all treatments effected a statistically significant mean percentage reduction in fluid flow relative to control discs that had been treated with saliva. Of the poly(alkyl methacrylate)s, PEMA and PBMA conferred the respective mean percentage reductions in fluid flow of $23 \pm$ 6 and $22 \pm 5$, but differences with respect to treatment with the anti-sensitivity benchmark control dentifrice $(16 \pm 7)$ did not reach statistical significance. Treatment with the PA18 positive control (disodium salt of a 1:1 octadecene-1/maleic acid copolymer; a material that is highly effective in increasing 
Table 3. Mean percentage reduction in flow of simulated dentinal fluid through etched bovine dentine discs after saliva treatment (baseline) and after a single $30 \mathrm{~s}$ treatment with a test agent (one-way ANOVA with a post hoc Fisher's test $(p<0.05)$; letters denote no significant difference between groups).

\begin{tabular}{ll}
\hline Polymer & $\begin{array}{l}\text { Mean\% flow rate } \\
\text { reduction }( \pm \text { SD) }\end{array}$ \\
\hline PEMA $(n=4)$ & $23(6)^{\mathrm{a}, \mathrm{b}}$ \\
PBMA $(n=5)$ & $22(5)^{\mathrm{a}, \mathrm{b}}$ \\
PHxMA $(n=5)$ & $3(4)^{\mathrm{c}}$ \\
PLMA $(n=5)$ & $14(5)^{\mathrm{b}}$ \\
PHMA $(n=4)$ & $12(6)^{\mathrm{b}}$ \\
POMA $(n=4)$ & $9(8)^{\mathrm{b}}$ \\
Water $(n=4)$ & $-3(6)^{\mathrm{c}}$ \\
SO $(n=4)$ & $16(7)^{\mathrm{a}, \mathrm{b}}$ \\
PA18 $(n=4)$ & $64(7)^{\mathrm{d}}$ \\
\hline
\end{tabular}

the hydrodynamic resistance of dentine discs in vitro [29]) conferred the greatest mean percentage reduction in fluid flow
$(64 \pm 7 \% ; p<0.05)$. The observed $16( \pm 7) \%$ reduction in dentinal fluid flow following brushing with the benchmark control is consistent with a SEM study by West et al [7], who reported that $17( \pm 5) \%$ of initially open tubules become fully or partially occluded following a 5 min brushing of the preetched human dentine surface with a $1: 4 \mathrm{w} / \mathrm{w}$ aqueous slurry of the same dentifrice.

To assess the cumulative effects of brushing with the polymer latexes, treatments were repeated 12 times with the application of saliva between each brushing, table 4 . Repeated application of each treatment effected considerable reductions in dentine permeability with respect to corresponding singleapplication treatments. The mean percentage reductions in fluid flow following twelve $30 \mathrm{~s}$ applications of the PEMA, PLMA or PHMA latexes were statistically equivalent $(p>0.05)$ at 60, 60 and 57, respectively, comparable to the $66 \%$ reduction effected by the control dentifrice. The reduction in dentine permeability effected by multiple applications of the PBMA latex (79\%) was significantly superior to that effected by the anti-sensitivity dentifrice

Table 4. Fluid flow (horizontal displacement of air bubble in tubing) across bovine dentine discs after saliva treatment (baseline) and after $12 \times 30 \mathrm{~s}$ treatments with each test agent. One-way ANOVA with a post hoc Fisher's test $(p<0.05)$; letters denote no significant difference between groups.

\begin{tabular}{|c|c|c|c|c|}
\hline Polymer & $\begin{array}{l}\text { Saliva treatment } \\
(\mathrm{cm} / 10 \mathrm{~min})\end{array}$ & $\begin{array}{l}12 \times 30 \mathrm{~s} \text { Polymer } \\
\text { treatment }(\mathrm{cm} / 10 \mathrm{~min})\end{array}$ & $\begin{array}{l}\% \text { Flow rate } \\
\text { reduction }\end{array}$ & $\begin{array}{l}\text { Mean\% flow rate } \\
\text { reduction }( \pm \mathrm{SD})\end{array}$ \\
\hline PEMA & 6.0 & 2.4 & 60 & \multirow[t]{4}{*}{$60(6)^{\mathrm{a}}$} \\
\hline PEMA & 4.0 & 1.357 & 66 & \\
\hline PEMA & 1.9 & - & - & \\
\hline PEMA & 1.3 & 0.6 & 54 & \\
\hline PBMA & 9.40 & 2.3 & 76 & \multirow[t]{5}{*}{$79(8)^{\mathrm{c}}$} \\
\hline PBMA & 0.636 & 0.2 & 69 & \\
\hline PBMA & 5.45 & 0.56 & 90 & \\
\hline PBMA & 4.5 & 0.7 & 84 & \\
\hline PBMA & 1.57 & 0.4 & 75 & \\
\hline PHxMA & 4.0 & 3.5 & 13 & \multirow[t]{4}{*}{$33(14)^{b}$} \\
\hline PHxMA & 4.3 & 2.45 & 43 & \\
\hline PHхMA & 0.455 & 0.273 & 40 & \\
\hline PHxMA & 4.4 & 2.8 & 36 & \\
\hline PLMA & 11.14 & 5.375 & 52 & \multirow[t]{4}{*}{$60(8)^{\mathrm{a}}$} \\
\hline PLMA & 1.125 & 0.45 & 60 & \\
\hline PLMA & 1.0 & 0.29 & 71 & \\
\hline PLMA & 8.2 & 3.7 & 55 & \\
\hline PHMA & 5.0 & 2.05 & 59 & \multirow[t]{4}{*}{$57(5)^{\mathrm{a}}$} \\
\hline PHMA & 7.0 & 3.5 & 50 & \\
\hline PHMA & 15.3 & 6.5 & 58 & \\
\hline PHMA & 28.6 & 10.86 & 62 & \\
\hline POMA & 2.67 & 2.0 & 25 & \multirow[t]{4}{*}{$35(8)^{\mathrm{b}}$} \\
\hline POMA & 4.7 & 3.0 & 36 & \\
\hline POMA & 5.0 & 2.78 & 44 & \\
\hline POMA & 2.0 & 1.3 & 35 & \\
\hline Water & 4.2 & 4.4 & -5 & \multirow[t]{4}{*}{$-9(4)^{d}$} \\
\hline Water & 2.73 & 3.1 & -14 & \\
\hline Water & 5.4 & 5.85 & -8 & \\
\hline Water & 3.3 & 3.55 & -8 & \\
\hline SO & 3.8 & 1.0 & 74 & \multirow[t]{4}{*}{$66(7)^{\mathrm{a}}$} \\
\hline SO & 0.8 & 0.31 & 61 & \\
\hline SO & 1.75 & 0.7 & 60 & \\
\hline SO & 4.0 & 1.33 & 69 & \\
\hline
\end{tabular}




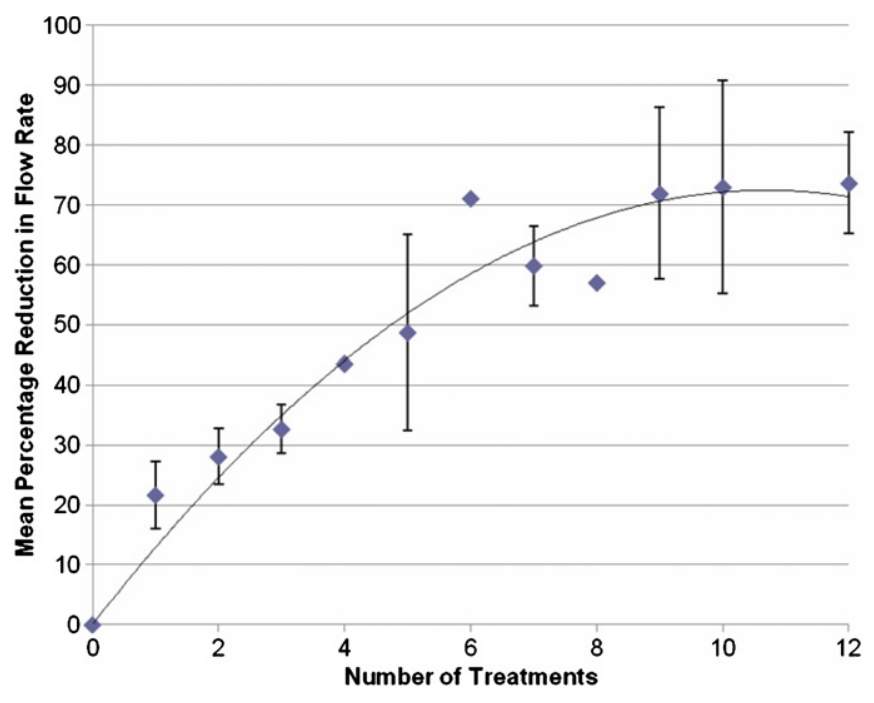

Figure 3. Cumulative mean percentage reduction in fluid flow across bovine dentine discs as a function of the number of $30 \mathrm{~s}$ treatments with the PBMA latex $(2.8 \% \mathrm{w} / \mathrm{w})$, relative to that effected by treatment with saliva alone; $n(1 \leqslant n \leqslant 5)$ is the number of repetitions of the 12-treatment protocol for each specimen; to identify the number of treatments necessary to effect a $70 \%$ reduction in fluid flow, measurements were taken after each treatment.

benchmark control $(p<0.05)$. PHxMA and POMA performed poorly in the $H_{c}$ model, yielding after 12 applications respective mean percentage reductions in fluid flow of 33 and 35 ; the capacity to effect dental occlusion was significantly inferior to that of the anti-sensitivity control dentifrice $(p<$ 0.05). The relatively good performance of PEMA, which exhibits poor film formation characteristics at $37{ }^{\circ} \mathrm{C}$, may be attributed to the physical blocking of dental tubules by large latex particles (about $200 \mathrm{~nm}$ ), or to improved film formation as a result of the suppression of the $T_{g}$ of this polymer following mixing with saliva. The contribution of each individual treatment, of the series of 12 , to the reduction in $H_{c}$ was investigated for the best performing latex, PBMA; the profile, figure 3 , shows that the progressive increase in tubule occlusion begins to wane at around the seventh treatment and effectively plateaus, at about $70 \%$, following the ninth successive treatment. Considering the substantive nature [30] of these films, the two materials that can be deposited onto teeth from aqueous media may enhance the performance of dental-hypersensitivity formulations.

\subsection{Stain prevention}

To test the hypothesis that non-permanent dental coatings function as barriers that may prevent or inhibit the uptake of stain chromogens by the underlying dental surface, pelliclecoated HA discs were treated either with water (negative control) or with the relevant polymer latex dispersion and immersed in a standardized stain solution. As expected, the $L^{*}$ values of pellicle-coated HA discs were significantly higher $(p<0.05)$ prior to exposure to the staining solution $(92.2 \pm$ $0.2)$ than the corresponding post-exposure values $(72 \pm 1)$, table 5. Groups of pellicle-coated HA discs treated with the
Table 5. Mean $(n=16 \pm \mathrm{SD}) L^{*}, a^{*}$, and $b^{*}$ values for stained control (pellicle-coated HA disc) and poly(alkyl methacrylate)-coated HA discs; letters c, d and e identify groups of polymers that do not exhibit statistically significant variations in performance ( $p<0.05$, one-way ANOVA, post hoc Fisher's test)

\begin{tabular}{llll}
\hline Test agent & $L^{*}( \pm \mathrm{SD})$ & $a^{*}( \pm \mathrm{SD})$ & $b^{*}( \pm \mathrm{SD})$ \\
\hline Control (pre-stain) & $92.2(0.2)^{\mathrm{c}}$ & - & - \\
Control (post-stain) & $72(1)^{\mathrm{d}}$ & $6(0.6)$ & $16(3)$ \\
PBMA & $81(3)^{\mathrm{e}}$ & $4(1)$ & $15(1)$ \\
PHxMA & $80(5)^{\mathrm{e}}$ & $4(2)$ & $15(3)$ \\
PLMA & $80(5)^{\mathrm{e}}$ & $4(2)$ & $17(3)$ \\
PHMA & $73(5)^{\mathrm{d}}$ & $7(1)$ & $17(3)$ \\
POMA & $73(2)^{\mathrm{d}}$ & $6(0.6)$ & $18(1)$ \\
\hline
\end{tabular}

shorter pendent chain polymers PBMA, PHxMA and PLMA exhibited greater stain resistance $(p<0.05)$, as measured by $L^{*}$, than the controls or the specimens that had been treated with PHMA or POMA, all of which failed to present any stainprevention benefit $(p>0.05)$. The values of $L^{*}$ for specimen groups treated with PBMA, PHxMA or PLMA could not be differentiated statistically $(p>0.05)$.

\section{Conclusion}

Poly(alkyl methacrylate)s have been formulated as aqueous latexes for use in dental care products. In vitro experiments have demonstrated the potential utility of one of these dental coatings, poly(butyl methacrylate), to offer protection against dental staining, dentinal hypersensitivity and acid demineralization.

\section{Acknowledgment}

The authors would like to thank GlaxoSmithKline Consumer Healthcare for supporting this research (PhD studentship to $\mathrm{BVN})$.

\section{References}

[1] Hannig C, Hamkens A, Becker K, Attin R and Attin T 2005 Erosive effects of different acids on bovine enamel: release of calcium and phosphate in vitro Arch. Oral Biol. 50 541-52

[2] Meurman J H, Rytomaa I, Kari K, Laakso T and Murtomaa H 1987 Salivary $\mathrm{pH}$ and glucose after consuming various beverages, including sugar-containing drinks Caries Res. 21 353-9

[3] Walters P A 2005 Dentine hypersensitivity: a review J. Contemp. Dent. Pract. 6 107-17 (http://www.ncbi.nlm.nih.gov/pubmed/15915210)

[4] Addy M 2000 Dentine hypersensitivity: definition, prevalence, distribution and aetiology. Tooth Wear and Sensitivity: Clinical Advances in Restorative Dentistry ed M Addy, G Embery, W M Edgar and R Orchardson (London: Martin Dunitz)

[5] Churchley D, Rees G D, Barbu E, Nevell T G and Tsibouklis J 2008 Low-surface-energy tooth coatings: an alternative approach to dental care Int. J. Pharm. 352 44-9

[6] ten Cate B 1996 The role of saliva in mineral equilibria-caries and calculus formation Saliva and Oral Health ed W M Edgar and D M O'Mullane (London: British Dental Association) 
[7] West N X, Hughes J A and Addy M 2001 The effect of pH on the erosion of dentine and enamel by dietary acids in vitro $J$. Oral Rehabil. 28 860-4

[8] Whitford G M 1987 Fluoride in dental products—safety considerations J. Dent. Res. 66 1056-60

[9] Tsibouklis J, Stone M, Thorpe A A, Graham P, Peters V, Heerlien R, Smith J R, Green K L and Nevell T G 1999 Preventing bacterial adhesion onto surfaces: the low-surface-energy approach Biomaterials 20 1229-35

[10] Tsibouklis J, Graham P, Eaton P J, Smith J R, Nevell T G, Smart J D and Ewen R J 2000

Poly(perfluoroalkylmethacrylate) film structures: surface organisation phenomena, surface energy determinations and force of adhesion measurements Macromolecules $338460-5$

[11] Derjaguin D V and Landau L 1941 Theory of the stability of strongly charged lyophobic sols and the adhesion of strongly charged particles in solutions of electrolytes Acta Physicochem. URSS 14 633-62

[12] Verwey E J W and Overbeek J T G 1948 Stability of Colloids (Amsterdam: Elsevier)

[13] Tunney M M, Gorman S P and Patrick S 1996 Infection associated with prosthetic devices Rev. Med. Microbiol. 7 195-205

[14] Churchley D, Barbu E, Ewen R J, Shen Z, Kim Y, McHugh M, Zhang Z Y, Nevell T G, Rees G D and Tsibouklis J 2008 Synthesis and characterization of low surface energy fluoropolymers as potential barrier coatings in oral care J. Biomed. Mater. Res. A 84 994-1005

[15] Tsibouklis J, Stone M, Thorpe A A, Graham P, Nevell T G and Ewen R J 1999 Surface energy characteristics of polymer film structures: a further insight into the molecular design requirements Langmuir 15 7076-9

[16] Berglin M, Andersson M, Sellborn A and Elwing H 2004 The effect of substrate molecular mobility on surface-induced immune complement activation and blood plasma coagulation Biomaterials 25 4581-90

[17] Suchanek W and Yoshimura M 1998 Processing and properties of hydroxyapatite-based biomaterials for use as hard tissue replacement implants Mater. Res. 13 94-117

[18] Mason S, Hamon R, Nolan A, Zhang H and Davison W 2005 Performance of a mixed binding layer for measuring anions and cations in a single assay using the diffusive gradients in thin films technique Anal. Chem. 77 6339-46
[19] Pashley D H and Matthews W G 1993 The effects of outward forced convective flow on inward diffusion in human dentine in vitro Arch. Oral Biol. 38 577-82

[20] Pashley D H, Matthews W G, Zhang Y and Johnson M 1996 Fluid shifts across human dentine in vitro in response to hydrodynamic stimuli Arch. Oral Biol. 41 1065-72

[21] Quirynen M, Marechal M, Busscher H J, Weerkamp A H, Darius P L and van Steenberghe D 1990 The influence of surface free energy and surface roughness on early plaque formation J. Clin. Periodontal 17 138-44

[22] Quirynen M 1994 The clinical meaning of the surface roughness and surface free energy of intra-oral hard substrata on the microbiology of the supraand sub-gingival plaque: result of in vitro and in vivo J. Dent. 22 S13-6

[23] Teughels W, Van Assche N, Sliepen I and Quirynen M 2006 Effect of material characteristics and/or surface topography on biofilm development J. Clin. Oral Implants Res. 17 68-81

[24] Adamson A W and Gast A P 1997 Physical Chemistry of Surfaces 6th edn (New York: Wiley)

[25] Dinelli F, Buenviaje C and Overney R M 2001 Glass transition measurements on heterogeneous surfaces Thin Solid Films 396 138-44

[26] Armstrong R D and Wright J D 1992 Impedance studies of poly ethylmethacrylate coatings formed upon tin-free steel Corros. Sci. 33 1529-39

[27] Diarra M, Pourroy G, Boymond C and Muster D 2003 Fluoride controlled release tablets for intrabuccal use Biomaterials 24 1293-300

[28] Hicks J, Garcia-Godoy F and Flaitz C 2004 Biological factors in dental caries enamel structure and the caries process in the dynamic process of demineralization and remineralization (part 2) J. Clin. Pediatr. Dent. 28 119-24

Hicks J, Garcia-Godoy F and Flaitz C 2004 Biological factors in dental caries enamel structure and the caries process in the dynamic process of demineralization and remineralization (part 2) J. Clin. Pediatr. Dent. 28214 (erratum)

[29] Dodd G P and Herms J K 2001 Oral care formulation for the treatment of sensitivity teeth US Patent No. 6241972

[30] Nielsen B V, Nevell T G, Barbu E, Rees G D and Tsibouklis J 2010 A thermogravimetric method for the assessment of the substantivity of polymer films on dentally relevant substrates J. Therm. Anal. Calorim. 102 121-6 